\title{
Use of a Remotely Operated Vehicle (ROV) to study marine phenomena: I. Pandalid shrimp densities
}

\author{
Bo I. Bergström ${ }^{1}$, J. Larsson ${ }^{1} \&$ J.-O. Pettersson ${ }^{2}$ \\ ${ }^{1}$ Kristineberg Marine Biological Station, S-450 34 Fiskebäckskil, Sweden \\ ${ }^{2}$ Institute of Marine Research, S-453 00 Lysekil, Sweden
}

\begin{abstract}
A new commercially developed ROV, the 'Sea OWl MK $I$, has been used to make density measurements of marine phenomena, especially pandalid shrimps, in the Gullmarfjord on the Swedish west coast. This note describes the ROV system and a simple attachment for measuring the area of a transect. An account of calibration and field procedures to make transects, together with some density and behavioural observations, are given to illustrate the usefulness of the method. In ten $260 \mathrm{~m}$ calibration transects, area estimates varied by only $3 \%$. In May 1985, shrimp density at depths of 80 to $115 \mathrm{~m}$ in the fjord was $0.33 \pm 0.03$ shrimps $\mathrm{m}^{-2}$. Shrimps were not attracted or repulsed by the strong light carried by the submersible. The ROV technique clearly shows potential for quantitative as weii as quaiilative woik.
\end{abstract}

Density measurements are crucial to any programme dealing with population or stock dynamics. Up to present time, densities of dermersal organisms at depths unattainable by SCUBA have been assessed with trawls and sledges. Density estimation with this kind of equipment is, however, only semi-quantitative, because of the difficulties involved in determining the area traversed by the sampling gear (Eleftheriou \& Holme 1984). Trawls and sledges are also size and species selective and do not function well on irregular or rocky surfaces; furthermore, these instruments often cause extensive disturbance to the substrate. To bypass the problem of area estimation, catch per unit effort (CPUE) data are widely used instead as a way to assess stock densities. Basic to CPUE measures are assumptions that (1) catch size is proportional to the absolute population density and (2) the proportionality factor remains constant between different sampling events. Densities can also be determined using mark and recapture techniques. However, impractically large numbers of organisms frequently have to be tagged, and mortality due to the tagging itself often hampers the usefulness of the method. In addition, recapture is mostly done by trawling, adding to the error.
Underwater cameras (photographic, cinematographic, video) have been used to make absolute density measurements of deeper living demersal species (Holme 1984). Three main modes of deploying cameras have been used: handheld by a diver, lowered on a cable, or towed behind a surface vessel. Kanneworff (1979) assessed densities of Pandalus borealis related to bottom area in Disco Bay (W. Greenland) with some success by using a lowered photographic camera fitted with an electronic flash and a bottom trigger. However, the usefulness of the method was limited by near bottom turbidity and the fact that shrimps were swimming well above the bottom. Howard (1982) studied the same species in the Farn Deeps (North Sea) using both photographic and video cameras which were towed behind a research vessel over the seabed at $80 \mathrm{~m}$ depth.

Because of a need to calibrate CPUE measurements with absolute density measures of pandalid shrimps, work to evaluate the usefulness of a newly developed Remotely Operated Vehicle (ROV), the 'Sea Owl Mk $I I^{\prime}$, was started at the Kristineberg Marine Biological Station (KMBS) in 1985. Although the ROV was initially developed to meet the demands of the off-shore industry and the military it was considered potentially useful for ecological studies at depths occurring across the continental shelf. This preliminary report demonstrates the scope of the 'Sea Owl Mk II' for biological studies on the continental shelf and presents its technical attributes along with density values and behavioural observations on Pandalus spp. from the Gullmarfjord. The potential for further development and work with other epibenthic and pelagic organisms is also discussed briefly.

Description of the ROV. The 'Sea Owl MkII' is an unmanned, tethered, remotely controlled submersible 
which can be operated to a depth of $350 \mathrm{~m}$. It is propelled by 7 thrusters allowing 3 -dimensional movement. The basic system consists of a submersible unit, an umbilical cable, a surface control console, and a power unit (Fig. 1). Technical data are presented in Table 1.

The submersible is equipped with a colour video camera mounted inside a dome, a manipulator, a photographic camera with electronic flash, and 2 independent, remotely controlled lighting systems (variable from 0 to $500 \mathrm{~W}$ each). The submersible is controlled through 2 'joysticks' and 2 sliding potentiometers located on the surface control console. Information is received through a video camera and the picture is presented on a monitor on the operator's console. Depth, heading, pitch, and roll angles are controlled by a microcomputer which is fed information from a depth sensor, pendulums, rate-gyros, and flux-gate compass. The technical design enables the submercible to automatically maintain its attained depth, attitude and compass heading. The submersible used in this study is equipped with 3-step power reduction on the thruster motors and a fine depth control which, when used either together or separately, give the operator fine control over horizontal and vertical movements of the ROV when it is working near extremely soft sediment.

In addition to the picture, depth, head, pitch and roll angles, real time and number of photographic ex- posures are all displayed simultaneously on the control monitor. Picture and digital information is recorded by a high resolution U-matic video recorder for permanent documentation as well as subsequent review.

Device for measuring length and width of a transect. In order to obtain density values, the area scanned by the 'Sea Owl' has to be measured. The width of the transect is defined by 2 vertical rods fixed $0.75 \mathrm{~m}$ apart in front of the submersible camera (Fig. 2). Transect lengths are measured using a flow meter (General Oceanics model 2030 with standard rotor) mounted on the 'Sea $\mathrm{OWl}$ '. The flow meter actually measures the distance travelled through water, but when no current is present or the current can be corrected for, the distance through water equals the distance travelled over the bottom. The flow meter is fixed to a frame which also supports 2 extra lights, in such a way that the flow meter is visible in the top part of the operator's monitor. The 2 extra lights shine downwards at an angle of about $90^{\circ}$ to the optical axis of the camera and are used to give an even illumination and to minimize backscatter (Fig. 2).

When making transects over muddy bottoms a pitch angle of $10^{\circ}$ was found to optimize detection of shrimps. Thus to ensure that the flow meter was held horizontally while the ROV moved along the transects, it was mounted at an angle of $-10^{\circ}$ to the horizontal axis of the submersible. When descending, ascending, or turning, the flow meter rotor is stopped by a simple

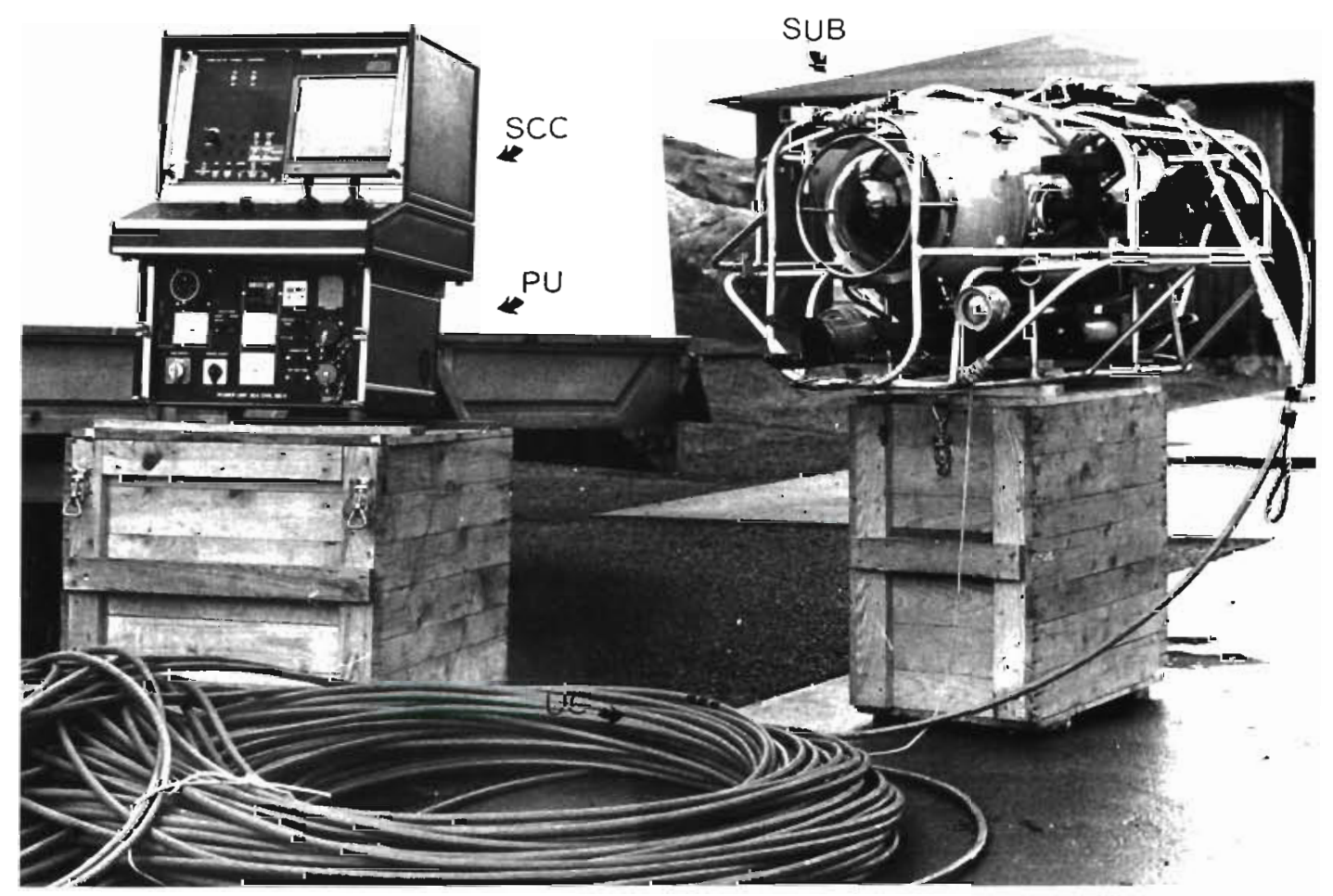

Fig. 1. The 'Sea OWl MkII' system. SUB: submersible unit; SCC: surface control console; PU: power unit; UC: umbilical cable 
Table 1. Technical description of the 'Sea Ow/Mk II'. The unmanned tethered remote controlled submersible consists of the following main units: Submersible; Umbilical cable; Surface control console; Power unit

$\begin{array}{lc}\text { Submersible } & \\ \text { Length: } & 1240 \mathrm{~mm} \\ \text { Width: } & 750 \mathrm{~mm} \\ \text { Height: } & 600 \mathrm{~mm} \\ \text { Weight in air: } & 90 \mathrm{~kg} \\ \text { Maximum operational } & \\ \text { depth: } & 350 \mathrm{~m}(1100 \mathrm{ft}) \\ \text { Maximum velocity: } & 2.5 \mathrm{kn} \text { forward, } 1.5 \mathrm{kn} \text { back- } \\ & \text { wards, } 1.1 \mathrm{kn} \text { sideways, } 1.0 \mathrm{kn} \\ & \text { up/down } \\ \text { Umbilical cable } & \\ \text { Cable length: } & 350 \mathrm{~m} \\ \text { Cable diameter: } & 14 \mathrm{~mm} \\ \text { Electrical connection: } & \text { Underwater UW connectors } \\ & \text { Surface MS connectors } \\ \text { Surface control console } & \\ \text { Length: } & 500 \mathrm{~mm} \\ \text { Width: } & 460 \mathrm{~mm} \\ \text { Depth: } & 600 \mathrm{~mm} \\ \text { Weight: } & 15 \mathrm{~kg} \\ \text { TV-monitor presentation: } & \text { Picture from colour TV-camera } \\ & \text { in submersible } \\ \text { Digital presentation of: } & \text { Heading, depth, pitch angle, } \\ & \text { roll angle, voltage, leakage } \\ & \text { and data-link failure warning } \\ \text { Power unit } & \\ \text { Dimensions: } & 440 \times 270 \times 470 \mathrm{~mm} \\ \text { Weight: } & 50 \mathrm{~kg} \\ \text { Input: } & \text { Adjustable } 190-250 \mathrm{~V} / \\ & 400-500 \mathrm{~V}, 50 / 60 \mathrm{~Hz} \\ \text { Output: } & 880 \mathrm{~V} \text { for vehicle; } 220 \mathrm{~V} \text { for } \\ & \text { auxiliary; } 220 \mathrm{~V} \text { for console } \\ & \text { equipment } \\ & \\ & \\ & \end{array}$

mechanism powered and controlled by the ROV's manipulator (Fig. 2).

The type of flow meter used in this study is widely used for pelagic sampling where it is normally suspended at the mouth of plankton nets. Due to the unconventional fixed mounting of the flow meter to the submersible, determination of an empirical rotor constant $(\mathrm{Rc})$ was necessary. Rc was determined from 10 calibration runs along a measured $(130 \mathrm{~m})$ line lying on the bottom. The submersible was steered out along the line, turned, and then steered back, making the total length of each run $260 \mathrm{~m}$. The average count (C) from these 10 runs was used to calculate Rc from the formula (given by the manufacturer): $\mathrm{Rc}=\mathrm{d} \times 999.999 / \mathrm{C}$ where $\mathrm{d}$ is distance traversed $(\mathrm{m})$. The rotor constant, calculated from the test runs, is 29.448 based on an average count of 8829 ( $\mathrm{SD} \pm 270.90$ ). Variation between counts in the 10 runs is thus approximately $3 \%$. In a transect of $260 \mathrm{~m}$ length and $0.75 \mathrm{~m}$ width the actual scanned area then amounts to $195 \pm 6 \mathrm{~m}^{2}$. A complication that might affect measurements is currents along the bottom. No such water movements were detectable during our transect runs, but if moderate currents are present, 2 transects can be made, the first against and the second with the current which should compensate for current error providing the 2 transects are similar in length. Future work will evaluate the accuracy of a low-speed rotor and also of a flow meter which gives electric impulses that can be interpreted and processed by the system's microcomputer: the aim is to provide calibration possibilities through the computer and to get a digital readout of the travelled distance on the screen, thus enabling the operator
Fig. 2. Attachment for benthic transects, showing flow meter with blocking device, rods to define width of transect, and extra lighting system

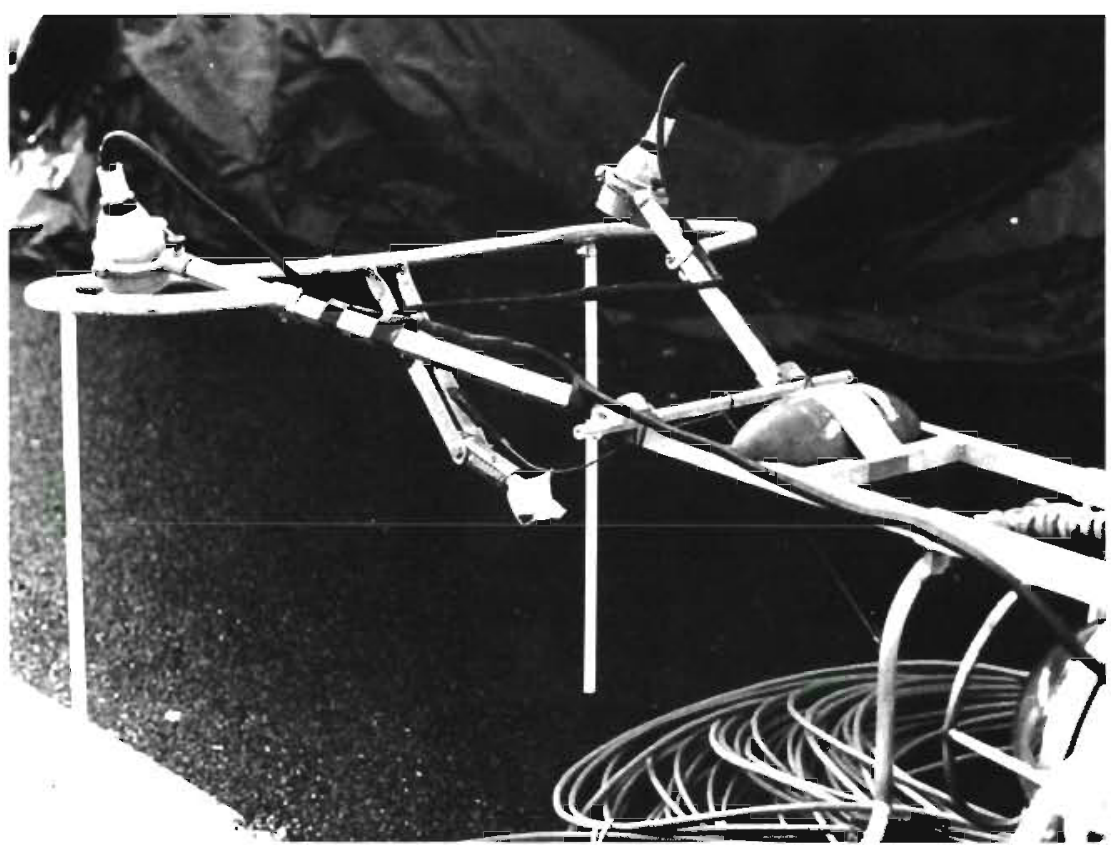


to compensate for possible currents during operation and providing simultaneous logging of distance and visual information.

Test site and field procedures. On 27 May 1986 the 'Sea Owl' was used along 3 transects at the site Gåsklåvan in the central part of the Gullmarfjord west coast of Sweden. Bottom depth at Gåsklåvan varies between 80 and $115 \mathrm{~m}$. The bottom consists of a very soft mudlike sediment. Dominating benthic fauna is burrowing and tube-building polychaetes and thyasirid bivalves (Dr. A. Josefson, Kristineberg Mar. Biol. Stn, Sweden, pers. comm.).

All transects started from the same point (max. distance $25 \mathrm{~m}$ ) and fanned out at angles of $20^{\circ}$. A flow meter reading was taken before descending with the submersible. At the bottom, before releasing the flow meter rotor, the very loose bottom sediment was gently stirred with the vertical sticks and the movement of the sediment cloud was used to indicate absence or presence of currents. After ensuring that no current was present, the rotor was released and a predetermined course line was steered until approximately all umbilical cable was run out. At this point the flow meter was again stopped and the submersible turned $180^{\circ}$. Using the lateral thrusters, the 'Sea Owl' was subsequently propelled laterally approximately 5 to $6 \mathrm{~m}$ and the return run begun with the rotor released. When the length of the umbilical cable approximately equalled the bottom depth on the return run the flow meter was stopped and the submersible brought to the surface where a new flow meter reading was taken. Picture information and simultaneous recordings of depth, real time, compass heading, roll and pitch angles were stored on videotape for subsequent analyses.

Observations during the test transects and scope for further work with shrimps. The transects traversed undisturbed areas and areas marked by trawl action. Undisturbed areas were covered with tube-dwelling polychaetes, but the trawled areas were trenched and furrowed by the action of otter boards and footropes, and polychaetes were practically absent.

Shrimp densities from the 3 transects are given in Table 2 and averaged $0.33 \pm 0.03$ shrimp $\mathrm{m}^{-2}$. The video recording does not allow us at this stage to distinguish between the 2 species Pandalus borealis and P. montagui which both occur in the fjord. How- ever, in samples taken with a shrimp-trawl on 26 April and 10 June at the same site, only $P$. borealis was present in samples of 765 and 207 shrimps respectively.

The density value found in our trial runs is much lower than those estimated from Disco Bay by Kanneworff (1979) and from Farn Deeps by Howard (1982). From 778 photographs Kanneworff (1979) found average densities of Pandalus borealis of 1.20 shrimps $\mathrm{m}^{-2}$ in October 1975 and 1.51 shrimps $\mathrm{m}^{-2}$ in October 1976. Howard reported a patchy distribution, the shrimps occurred either solitary with a density of 1 shrimp $\mathrm{m}^{-2}$ or in denser groups clustered around the sea anemone Bolocera tuediae. Further work with the 'Sea Owl' in combination with trawling will reveal if the relatively low values from our test transects are representative of the shrimp stock in the Gullmarfjord. In our transects shrimps were only seen sitting on the bottom. Along one transect 3 shrimps were seen sitting close to each other near a cerianthid anthozooan. No free-swimming pandalids were observed during several test runs between 5 and $15 \mathrm{~m}$ above the bottom made in conjunction with the transects.

The usefulness of the ROV for density studies of pandalid shrimps would be seriously hampered if these crustaceans reacted to the submersible either by attraction or repulsion. We did not observe any such reaction, however. When the lights shone on the shrimps they remained still; only if touched by the submersible would the shrimps flick away 1 to $1.5 \mathrm{~m}$. Future work on pandalids with this method will concentrate on comparisons of density values obtained with the submersible with CPUE data from trawling. The planned procedure includes making transects before setting the trawl at the same site and during the same fishing day. The ROV will also be used to compare shrimp densities on trawled and undisturbed areas.

Discussion. Holme (1984) has discussed photographic information gathering. Photographic or video surveys were regarded as suitable for surveys of particular large species living on the sediment surface. However, species identification from pictures needs initial corroboration by the examination of actual specimens from the same habitat. Our experience agrees with these statements.

Table 2. Shrimp transects, Gåsklåvan, Sweden, 27 May 1986. Rotor constant: 29.448. Transect width: $0.75 \mathrm{~m}$

\begin{tabular}{|ccccccc|}
\hline Transect no. & Time $(h)$ & Heading & Depth $(\mathrm{m})$ & Transect area & No. of shrimp & No. of shrimp m ${ }^{-2}$ \\
\hline 1 & $1017-1041$ & $300-120^{\circ}$ & $91-106 \mathrm{~m}$ & $207.9 \pm 6.2$ & 64 & $0.31 \pm 0.01$ \\
2 & $1154-1216$ & $320-140^{\circ}$ & $89-112 \mathrm{~m}$ & $239.7 \pm 7.2$ & 88 & $0.37 \pm 0.01$ \\
3 & $1253-1315$ & $280-100^{\circ}$ & $88-105 \mathrm{~m}$ & $259.7 \pm 7.8$ & 84 & $0.32 \pm 0.01$ \\
\hline
\end{tabular}


The present submersible can be used over both soft and rocky substrates and also in the water column between the surface down to $350 \mathrm{~m}$ of depth. With only simple attachments, accurate quantitative data of species having suitable size can be obtained and stored for subsequent analysis as demonstrated for pandalid shrimps in this report. Additionally, the scope for non-disturbing behavioural studies, e.g. by the use of low light video cameras, and for combining the ROV with sampling devices (e.g. plankton nets, slurpguns, water samplers, sediment corers etc.), have yet to be assessed. Furthermore, by using the manipulator, items can be placed, retrieved and manipulated at depths and under conditions that do not allow scientific diving (e.g. in deep water under ice-cover, in shark-infested areas), thus allowing in situ experiments to be carried out. A clear advantage compared to diving is that the operation time at depth is only limited by the endurance of the pilot working on the surface.

The 'Sea Owl' is more versatile than epibenthic photosledges and lowered cameras. First, the ROV does not have to be towed to perform the same function as a sledge. Second, it can be immediately stopped during the survey transect and items can be inspected and documented from close range and from different angles. Third, a ROV can be used just as well on a vertical rockface as on a smooth soft bottom. Fourth, the ROV can be used for pelagic work, e.g. for making density estimates of scyphomedusae and of other macroplanktonic organisms, providing a frame and a flow meter is attached.

The cost of operating a manned research submers- ible is beyond the reach of most workers in marine sciences. From our present experience with the 'Sea Owl Mk II', the scope for work with Remotely Operated Vehicles is clearly promising and further applications in the fields outlined above await exploration.

Acknowledgements. The submersible used in this study was financed by a grant from the Swedish Council for Planning and Coordination of Research. It is owned and operated by the 'Sea Owl consortium' comprising 9 Swedish institutions representing marine and fisheries biology, underwater technology and archaeology. The Swedish National Marine Resources Commission has played an important role in the formation and maintenance of the consortium. We also acknowledge our gratitude to the manufacturer, Scandinavian Underwater Technology (SUTEC), for substantial technical and material support. The Pandalus project is sponsored by the Kristineberg Marine Biological Station to which we extend our gratitude, especially to Prof. J.-O. Strömberg for his constant support and to the crew of the R/V Arne Tiselius, Berne Petersson and Christer Gren for their help with field work.

\section{LITERATURE CITED}

Eleftheriou, A., Holme, N. A. (1984). Macrofauna techniques. In: Holme, N. A., McIntyre, A. D. (ed.) Methods for the study of marine macrobenthos. IBP Handbook No. 16 Blackwell, Oxford, p. 140-216

Holme, N. A. (1984). Photography and television. In: Holme N. A., McIntyre, A. D. (ed.) Methods for the study of marine macrobenthos. IBP Handbook No. 16, Blackwell, Oxford, p. 66-98

Howard, F. G. (1982). Of shrimps and sea anemones; of prawns and other things. Scott. Fish. Bull. 47: 39-40

Kanneworff, P. (1979). Density of shrimp (Pandalus borealis) in Greenland waters observed by means of photography. Rapp. P.-v. Réun. Cons. Int. Explor. Mer 175: 134-138 